\title{
An Economic Analysis of Urban Traffic Congestion
}

\author{
$\mathrm{Yu} \mathrm{Fu}$ \\ Beijing Jiaotong University, Beijing, China \\ 16120508@bjtu.edu.cn \\ Yu Fu
}

Key words: Traffic congestion; Economic analysis; Countermeasures and Suggestions.

\begin{abstract}
Urban traffic congestion has become a very serious problem that many countries face in the process of urbanization in recent years. Advances in science and technology have brought about the development of the national economy and the improvement of living standards of residents. The number of private cars has soared, bringing unprecedented traffic congestion to urban transport. Traffic congestion poses a great threat to the healthy development of urban economy in our country. It not only causes economic costs, but also brings about time costs and damages to the environment. This article mainly analyzes the traffic congestion from the economic point of view and puts forward practical suggestions for the urban traffic congestion in China.
\end{abstract}

\section{Introduction}

With the improvement of people's income level and the stimulation of domestic demand, the number of private cars in our country has been developing rapidly. Residents traveling more and more rely on private motor vehicles. However, the existing urban planning and transportation infrastructures in our country are hard to adapt to the high growth demand of private trips. In particular, some cities are limited by the urban land area and the road infrastructure is difficult to expand. This imbalance between supply and demand has resulted in Today's heavily congested roads. Road congestion is the result of a combination of many factors. The rapid accumulation of urbanization has an increasing demand for urban transportation networks, and the development of transport infrastructure has in turn promoted urbanization. Therefore, solving urban traffic congestion and forming a good network of transportation infrastructure play a crucial role in the healthy development of the city.

\section{Urban traffic congestion generated by the economic analysis}

\subsection{Urban road transport system supply and demand conflicts}

\subsubsection{Demand Factors}

From the traffic demand point of view, the total traffic demand continues to grow, the rapid growth of travel and travel distance continues to lengthen, compared with the 2012-2014 Beijing city data, as shown in the following table. In 2012, the road length in Beijing was $79,000 \mathrm{~km}$. In 2013, the road length was still 0.79 million $\mathrm{km}$. In 2014, the length of the road was $81,800 \mathrm{~km}$. The average annual growth rate of road length in two years was $1.26 \%$. In 2012, the private car ownership in Beijing was 4.0555 million. In 2013, the private car ownership was 4.2495 million. In 2014, the private car ownership was 4.3579 million units, with an average growth rate of $3.67 \%$ over two years. As shown in the table, the growth rate of road area in 2013-2014 in Beijing was negative, while that in 20122013 and 2013-2014 was greater than the growth rate of road length and the growth rate of road area. From this we can see that one of the most direct reasons for the congestion is that the growth in the number of cars exceeds the growth in road construction. 
Table 1. Beijing traffic data

\begin{tabular}{cccccc}
\hline Indicator (year) & 2012 & 2013 & 2014 & $\begin{array}{c}2012-2013 \\
\text { growth rate }\end{array}$ & $\begin{array}{c}2013-2014 \\
\text { growth rate }\end{array}$ \\
\hline $\begin{array}{c}\text { Length of road (ten } \\
\text { thousand kilometers) }\end{array}$ & 0.79 & 0.79 & 0.81 & 0 & $2.53 \%$ \\
\hline $\begin{array}{c}\text { Road area (million square } \\
\text { meters) }\end{array}$ & 13509 & 13884 & 13834 & $2.78 \%$ & $-0.36 \%$ \\
\hline $\begin{array}{c}\text { Private car ownership (ten } \\
\text { thousand) }\end{array}$ & 405.55 & 424.95 & 435.79 & $4.78 \%$ & $2.55 \%$ \\
\hline
\end{tabular}

\subsection{2 supply factors}

From the perspective of transportation supply, insufficient investment in urban transport infrastructure will result in the mismatch between the spatial structure and the functional structure. By the end of 2012, the total mileage of the national highway was $42,375,000 \mathrm{~km}$, an increase of $131,100 \mathrm{~km}$ from the end of 2011. In the face of the rapid urbanization, the public transport resources are relatively insufficient, the road network structure is irrational, and it is impossible to transport the evacuation flow quickly and timely.

\subsection{The external effect of urban road traffic system}

Urban roads belong to a common source to car owners. With the purchase of a car, consumers can use urban roads without having to pay extra for road use. When the city has convenient transportation facilities, more and more people buy cars and their travel volume increases substantially. At this time, the external effects begin to emerge, that is, people only decide whether or not to travel based on their own travel cost and travel revenue when traveling, without considering whether the increase in travel costs of other travelers caused by aggravating the road congestion. So at this time there has been a departure from the individual behavior and collective behavior, the result is that the actual amount of travel is greater than the social optimum amount of travel, personal optimization is not a collective optimization. The result is more and more vehicles on the road, causing more and more serious traffic jams.

As shown in the figure below, Curve D represents the traffic demand curve, MSC represents the social marginal cost of transportation, that is the additional cost per additional car on the road which includes the additional cost of the car after the addition of a car on the given road and the additional cost of other vehicles due to traffic jams caused by the increase of the car MC represents the added cost of transportation for a given vehicle trip. The inconsistency between personal cost and social cost has negative negative effect. The negative externalities here do not refer to the problems of environmental pollution and traffic safety brought by the Transport Department. It is the cost of slowing down due to excessive traffic flow.

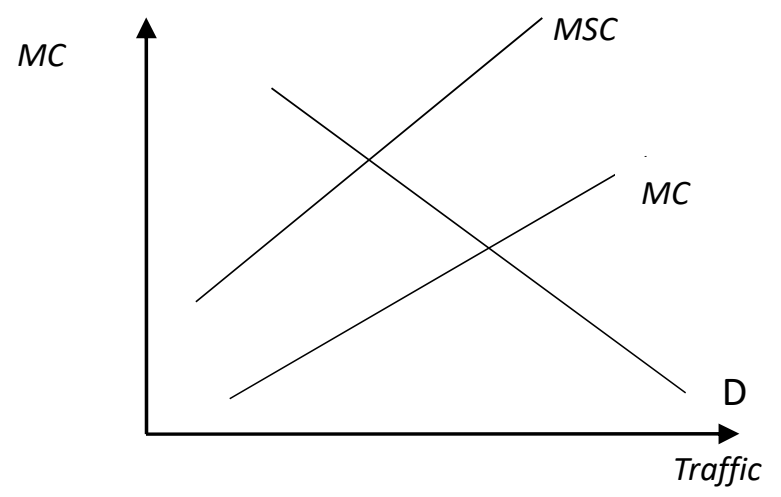

Fig. 1. Cost demand curve 


\section{Solutions to traffic congestion and suggestions}

The Downs law states that with the government's ineffective control over urban traffic, new road facilities will always induce new traffic, and traffic demand will always tend to outpace traffic. In other words, no matter how the government constructs and broaden the road, as long as the government does not control effective traffic demand, the problem of traffic congestion will not be improved. This also gives us a way to ease traffic congestion. From the demand side, improve people's travel costs, reduce unreasonable traffic demand, from the supply side, focusing on optimizing the supply structure.

\section{1 traffic demand management}

\subsection{1 receive congestion fees}

Set reasonable congestion costs in order to curb the amount of travel, reduce people's travel needs, and increase travel costs. The purpose of collecting the congestion charge can make the road users pay the actual social marginal cost. That is using the economic lever to internalize the negative external effect caused by traffic congestion on the urban road through the form of charging, to limit the travel of motor vehicle users during peak hours, to achieve the optimal use of urban transport resources.

\subsubsection{Reduce official vehicles}

Reduce traffic pressure by reducing official vehicles. In the United States, for example, a department of several thousand people in the U.S. federal government usually has only dozens of official vehicles. The state government official car only 10 vehicles, the municipal government official car only a few or not even. The U.S. government tends to spray the words "government vehicles" on public-service vehicles to facilitate public supervision and eliminate public use of buses.

\subsection{Supply Factors Management}

Developed public transport can largely ease traffic congestion. By increasing the input of public transport facilities, alleviating the supply contradictions, making public transport more convenient, the development of a reasonable public transport fares and increase public transport subsidies. This will help attract more passengers to public transport.

\subsection{Guide the public to establish awareness of green traffic trip}

After analyzing some objective control measures to control traffic congestion in urban areas, the government should also start with people's consumption concept and traffic travel awareness, and guide the public to establish a green concept of traffic travel. With the development of modern society, people think that owning a car is a status symbol, and this sense of consumption leads to the number of private cars rapid growth. In the process of urbanization and motorization, the government should guide the public to recognize the time and cost caused by traffic jams, prompt people to change their concepts and establish a modern civilization concept of transport to encourage citizens to travel green.

\section{Summary}

The problem of urban traffic congestion has become a serious obstacle in the process of urban development. It not only gives travelers time, economy and other costs, but also causes waste of resources and pollution of the environment. This paper mainly analyzes the mechanism of urban traffic congestion from the perspective of supply demand and externalities in economics, and finally puts forward measures to stop the congestion from the supply demand. With a view to alleviate the problem of urban traffic congestion, to a certain extent, promote the city's sustainable development.

\section{References}

[1] Liu Zhiyan, Yue Xiaoyan etc. The Cause of Urban Traffic Congestion and Countermeasures in China[J]. Urban Social Management, 2011, 18(11): 90-96 
[2] Ou wen, Wang Xiaofang. The Economic Analysis of Urban Traffic Congestion [J].

Theoretical discussion, 2011, (11)

[3] Wang Siyao, Li Ruoshui etc. An Economic Analysis of Traffic Congestion [J]. Management, 2011,33 (7):13-15.

[4] Xv Dongyun. New Development of Urban Traffic Congestion Management Model [J]. Integrated transport, 2007 (5).

[5] Xv Zhao, Ou Guoli. The Theoretical Basis and Policy Analysis of Traffic Congestion Charges [J] China Industrial Economy, 2012, (12).

[6] Yang Guangcan. Analysis of Urban Traffic Congestion in Shanghai and Suggestions [D]. Shang Hai: Tong Ji University, 2008.

[7] National Bureau of Statistics of the People 's Republic of China. National statistical database [EB/OL].[2016-11-26]. http://data.stats.gov.cn/easyquery.htm? $\mathrm{cn}=\mathrm{C} 01 \& \mathrm{zb}=\mathrm{A} 0 \mathrm{G} 0 \mathrm{I} \& \mathrm{sj}=2014$.

[8] Zhu Minghao. Analysis on the Social and Economic Impact of Urban Traffic Congestion [D]. BeiJing: BeiJing Jiaotong University, 2013. 